\title{
CLAIMS FREQUENCY AND RISK PREMIUM RATE AS A FUNCTION OF THE SIZE OF THE RISK *
}

\author{
Gunnar Benktander \\ Zurich
}

I.I The rapid economic growth in the last decade and the fierce competition have forced industry to raise its output, to develop new manufacturing methods and, where possible, to lower the fixed costs per unit of output. Consequently bigger factories and warehouses have been and are being built. Furthermore increasing labour costs have speeded up rationalisation and the introduction of efficient machinery.

I.2 Often, in the course of this development, too little attention has been paid to safety. This is reflected in the increasing number of Fire and Consequential Loss claims which have become so costly that the premium income has proved inadequate. Insurers have therefore adjusted their tariffs and increased their rates.

I.3 Of course, this is no solution to the problem. Insurers have to insist on adequate fire prevention and fire protection measures. Progress in the right direction can certainly be expedited by realistic tariffs which take account of all the positive features (sprinklers, inspection reports, etc.) and the negative features of a given risk (in commerce or industry).

I.4 Rating experts say that the tariffs of industrialized countries do not always point to the actual risk and claims fluctuations; one very important factor here, the size of the risk or of the building (i.e. its insured value, volume, surface area), brings me to the main theme of my today's talk.

2.I It has been known for years that the size of an object and the concentration of high values within a limited area has an influence on claims frequency and on the pure risk premium.

2.2 Insurance will constantly have to update its experience data in this field if insurers want to be in a position to calculate

* English translation of an invited lecture delivered in German at the Igth International Congress of Actuaries, Oslo, 1972. 
adequate and fair premium rates for clients in commerce and industry.

2.3 International comparisons are, no doubt, extremely important in this sector. Factories and warehouses of above-average size imply an increase of the risk, however, this increase can be counteracted by measures in the field of fire prevention and fire protection. Economic development and the ever-increasing concentration of values lead us to assume that the problems connected with the size of the risk will acquire even greater importance in future.

2.4 As previously mentioned, it has been known for years that the size of a risk influences the claims frequency and the risk premium or fire loss ratio as it used to be called. Permit me to begin with a quotation:

3.r "It is an interesting question what influence the size of a risk has on the fire loss ratio, given that all other factors are equal.

Theoretically one can approach the solution of this problem as follows: the larger a risk, the more likely an outbreak of fire under otherwise equal circumstances. This proposition can be illustrated by examples. If a block of roo flats is compared with a single flat, it is obvious that there is more likelihood of fire breaking out in the former case for there are more stoves, more light fittings and, of course, more people. Where there is a human being there is also his carelessness and his ineptitude in using fire. The same can be said of a factory: the larger it is, the more mechanisms it contains, the more processes are used which are susceptible to fire, quite apart from the number of people. The same conclusions are valid for warehouses.

Thus one can hardly contest the opinion that if all other factors are equal, the likelihood of fire appears to be greater, the larger the risk. If the degree of damage did not decrease, one could then make the positive assertion that the fire loss ratio increases in line with the size of the risk. In respect of certain risks consisting solely of inflammable material (such as hay and straw barns, woodpiles and wooden mills etc.), where, if fire breaks out, a total loss usually results, there are sufficient factors to substantiate this proposition.

However, as far as risks of fire-proof or semi fire-proof construc- 
tion are concerned, the degree of damage will generally decrease with the increasing size of the risk. If the size moves in the opposite direction from the charges in the likelihood of fire, the fire loss ratio may remain constant. Since, however, there is still a possibility that a large risk, even of fire-proof construction, may be fully destroyed, one must assume that the fire loss ratio of large risks must, also in this case, be greater than that of small risks. There is only one objection to this assertion, which is frequently raised, i.e. that large risks are usually better protected against fire."

3.2 The above quotation is taken from Sergowskij's famous book on Fire Insurance, written in 1924 in Ljubljana. The German version "Theorie der Feuerversicherung" was published in Prague in $\mathrm{r} 93 \mathrm{I}[24] . *$

4.I In this field - as in many others - one can distinguish between a rather theoretical line based on well-contrived trains of thought and a more practical line based on statistical data. Both components are important and the interplay between them has enriched our knowledge.

4.2 A Russian, Professor Sergius von Sawitsch, was the first person to conduct studies into this field. He did so in I907 in Petersburg [23].

Von Sawitsch studied a homogenous risk, of which:

(I) the likelihood of ignition is equal at all points,

(2) the fire spreads from one point to another in a straight line and

(3) the probability that fire will spread from one point to another is simply a function of the distance between them - where the probability decreases as the distance increases.

4.3 On the basis of the first premise, the claims frequency $f$ can be expressed as follows:

$$
f=A V
$$

$V$ signifying the volume or value of the risk.

4.4 We proceed from the logical assumption that in case of fire, the average loss $G$ increases with the value of the risk. Thus we arrive at the following formula for the pure risk premium:

$$
p=A V \cdot \frac{G(V)}{V}=A G(V)
$$

* The numbers in brackets refer to the List of References. 
4.5 Von Sawitsch studied the function $G(V)$. He introduced a so-called coefficient of fire spread which was dependent on the construction and the material of the insured object. If the coefficient is I, there will only be total losses. Generally it is lower than I. Von Sawitsch used six double integrals and finally came to the conclusion about the increase of the risk premium in line with the risk volume.

5.I Interest in this problem then shifted from Petersburg to Finland, where, 25 years later in 1932, the chief actuary of an insurance company in Turku, H. Eklund, popularised and further developed in an interesting discussion [I5] the theory of von Sawitsch. Eklund referred back to Sergowskij whom I previously mentioned and to the German Professor Riebesell [22].

5.2 In 1937 Sergowskij wrote:

Fire loss ratio equals claims frequency times the average degree of damage.

He described this expression as the basic equation of the fire loss ratio. This basic equation applies to separate buildings of the same insurance value. In this case, the solution of the equation gives the same result as the direct division of the loss amount by the sum insured.

5.3 If this is not the case, the "full equation" for the fire loss ratio must be used:

Fire loss ratio equals the probability of outbreak of fire times the coefficient of contagion times value of risks affected times average degree of loss.

5.4 It is common knowledge that the claims frequency equals the probability of outbreak of fire times the coefficient of contagion.

The coefficient of contagion is I if there is no possibility of fire spreading from one building or risk to another. Otherwise it is greater than $\mathrm{I}$.

5.5 The "weight of the risks affected" is the average sum insured of the risks involved divided by the average sum insured of the totality of all risks. A weight factor which is greater than I, which is almost always the case, shows a "progression" (i.e. increase with size) in the claims frequency.

5.6 To illustrate this, I will give you the average weight factor of the 18 Swiss Cantonal Fire Insurers during the decade r928-1937; 
it amounted to 3.25. The average sum insured of the risks involved amounted to Sw. frs. 85.047.-, that of all risks to Sw. frs. 26. I53.Of the 180 (I8. ro) individual weight factors, 179 were greater than I and one (Canton Glarus I930) was lower than I (0.93).

5.7 Eklund quoted a few weight factors but did not possess any statistics to further illustrate the progression of the claims frequency and the fire loss ratio.

6.I It is not so far from Turku to Stockholm and 5 years later, in 1937, P. O. Berge demonstrated on the basis of Swedish dwellings how the claims frequency and the fire loss ratio increase with the size of the house (measured by its insured value). Berge spoke about his results to the Institute of Swedish Actuaries. In the same year, they were published in a study prepared for the International Congress of Actuaries in Paris [6].

6.2 In addition, Berge pointed out that little is known about the effects (risk of contagion) of a fire on other buildings. He briefly outlined a plan for statistical studies to determine the influence of distance and other decisive factors. Such studies were later carried through in Sweden and other countries.

6.3 Other researches have frequently quoted Berge's findings and I, for my part, should like to quote some of his figures. On the basis of his company's statistics, Berge drew up the following table for wooden dwellings for the years I930-r934.

\begin{tabular}{ccc}
\hline $\begin{array}{c}\text { Sum insured } \\
\text { on the building } \\
\text { in Sw.Kr. }\end{array}$ & $\begin{array}{c}\text { Claims } \\
\text { frequency } \\
\text { in } \%\end{array}$ & $\begin{array}{c}\text { Degree of } \\
\text { loss } \\
\text { in } \%\end{array}$ \\
\hline o- I0.000 & I.3 & 21.5 \\
10.000- 20.000 & 3.4 & 13.0 \\
20.000-40.000 & 5.2 & 8.6 \\
40.000-70.000 & 9.6 & 7.3 \\
70.000-130.000 & 12.9 & 5.5 \\
130.000-200.000 & 20.2 & 4.0 \\
\hline
\end{tabular}

After graphic levelling, the following figures were obtained: (see page 124).

6.4 The figures appear to confirm von Sawitsch's theoretical results for "homogeneous risks", for the fire loss ratio increases constantly as a function of the size. The increase is particularly marked with small sizes of building. 


\begin{tabular}{|c|c|c|c|}
\hline $\begin{array}{l}\text { Sum Insured } \\
\text { in Sw.Kr. }\end{array}$ & $\begin{array}{l}\text { Claims } \\
\text { Frequency } \\
\text { in } \% 0\end{array}$ & $\begin{array}{l}\text { Degree of } \\
\text { Loss } \\
\text { in } \%\end{array}$ & $\begin{array}{l}\text { Risk } \\
\text { Premium } \\
\text { in } \% 00\end{array}$ \\
\hline I0.000 & 2.4 & 14.8 & 0.36 \\
\hline 40.000 & $7 \cdot 3$ & $7 \cdot 7$ & 0.56 \\
\hline 70.000 & I I. 2 & 6.2 & 0.69 \\
\hline roo.000 & 14.7 & 5.4 & 0.79 \\
\hline I30.000 & 17.5 & 4.8 & 0.84 \\
\hline
\end{tabular}

7.I When it was published, this statistical material aroused considerable interest in the problem on the European Continent, especially in France and in Italy. Due to the work of Sergowskij and Riebesell an interest already existed in Germany.

7.2 In 1940 in Italy, Professor R. d'Addario [I] showed that on the basis of Berge's figures, the claims frequency can be expressed as a function of the size (sum insured) as follows:

$$
f(s)=A \cdot s^{\alpha}
$$

and the average degree of loss

$$
g(s)=B \cdot s^{-\beta}
$$

The risk premium rate is therefore

or

$$
r(s)=f(s) \cdot g(s)
$$

$$
r(s)=A \cdot B \cdot s^{\alpha-\beta}
$$

He arrived at an $\alpha$ of 0.77594 and a $\beta$ of 0.43759 .

Consequently $\alpha-\beta=0.33835$.

These functions give a good description of the Swedish statistics. 7.3 In I956, Blandin, France [9], applied the same method to Berge's figures and to the French statistics. Later, Depoid gave same additional data in France in his valuable book [13]. He applied the same model.

7.4 In technical literature the claims frequency formula

$$
f(s)=A \cdot s^{\alpha}
$$

is attributed to Blandin and not to d'Addario which would be more correct. I'll leave it to the two Latin sister nations to settle this point. 
8.I The studies recently carried out in Italy by Miss G. Ferrara on the basis of statistics furnished by the "Concordato Italiano Incendio" are both topical and interesting [I6]. For the various Italian industrial groups she applied Professor d'Addario's formulas and arrived at the following values for the parameters $\alpha$ and $\beta$.

\begin{tabular}{|c|c|c|c|c|}
\hline & Period & $\alpha$ & $\beta$ & $\alpha-\beta$ \\
\hline \multirow{2}{*}{$\ldots$} & $\begin{array}{l}\text { r963--65 } \\
\text { r966-67 }\end{array}$ & $\begin{array}{l}0.53 \\
0.47\end{array}$ & $\begin{array}{l}0.74 \\
0.75\end{array}$ & $\begin{array}{l}-0.21 \\
-0.28\end{array}$ \\
\hline & $1963-67$ & $0.5 \mathrm{r}$ & 0.74 & -0.23 \\
\hline
\end{tabular}

In addition a $\alpha$ of 0.50 resulted for the period r968-69.

8.2 I recently had an opportunity to visit $M$. Tribouillois, France [25] and to study the statistical data for French industry for the years I968, I969 and I970. Here too, the $\alpha$ was around 0,50 . In other words

$$
f(s)=A \cdot s^{0,5}
$$

8.3 In fact, there was a great similarity between the French and Italian figures. This means that not only $\alpha$ but also the claims frequency level expressed in the parameter A was similar (account having been taken of the exchange rate Italian Lire/French Franc).

8.4 In the five-year period r963-67 analysed by Miss Ferrara, the claims frequency increases continuously with the size of the risk, from $33 \%$ in the smallest class of risks (below roo million lire) to $846 \%$ in the largest class of risks (over ro milliard lire). The description by means of the function $f(s)=A \cdot s^{\alpha}$ is very good. The average degree of loss decreases, but not very regularly and is therefore less suitable for an analytical description. However, it must be borne in mind that the statistical data, deriving from different branches of industry, is not homogeneous.

9.I In Holland, Dr. Pestman has analysed the so-called Provincial Fire Insurance Business [I8]. He investigated how the risk premium rate increased if the size of the building is doubled and arrived at the following factors: I,59, I,6I, I,59, I,49, which gives an average value of $\mathrm{I}, 57$. In the risk premium formula

$$
r(s)=C \cdot s^{r}
$$


this average increase of $I, 57$ corresponds to a $\gamma=\alpha-\beta$ of 0,65 . This figure is high, but it must be borne in mind that rustic buildings are involved.

I0.I The interest in the size factor persisted in Scandinavian countries for decades. The mutuals are cooperating in the statistical field and regularly publish reports on their results [I2].

I0.2 Hans Andersson carried on Berge's work.

I0.3 In Denmark, the largest insurer of buildings preparedalready in I847-statistical data for the period of I828-1845 regarding the size of risks. In this same company, Due-Jensen, Knud Knudsen and Henning Kjaer have done outstanding work on statistics over the past 3-4 decades. Using data from a different group of companies, Dr. Paul Johansen has also contributed valuable work $[\mathbf{I} 7]$.

I0.4 In connection with the said Scandinavian cooperation on statistics, the names of the Norwegians, C. Schweder and A. Rydning and the Finn H. Storgårds may be mentioned.

I0.5 The Non-Life actuaries of the Scandinavian stock Companies have also studied the size factor but have published practically none of their findings. I will therefore mention only two of the leading names in our host country, namely Henning Hellemann and Lars Wilhelmsen.

II.I Maybe you will allow me to say a few words about my own work in this particular field. During the I5 years I944-I959 I had the opportunity to serve the Union of Swedish local Fire Mutuals. Inspired by the works of von Sawitsch, Sergowskij and Berge, I started to collect and analyse claim figures emanating from the insurance of more than one million buildings.

II.2 In comparison with the statistician working on industrial figures I was in a good position as the statistical data at my disposal was large and relatively homogeneous.

II.3 Following von Sawitsch I tested whether the claims frequency was proportional to the size (measured by the sum insured s). The fit was not particularly good. However, through a slight modification of the formula a substantial improvement in the description of data was achieved. Within each category of risks the claims frequency was constituted by two elements. To an element independent of size an element increasing in direct pro- 
portion to the size had to be added. The mathematical formula was as follows:

or, in diagram form, a straight line.

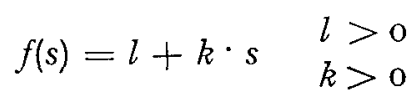

II.4 However, it was more important to find a mathematical description of the variation of the pure risk premium rate with the size of the building measured by the sum insured. The natural step was to try to supplement the knowledge obtained regarding the claims frequency by special studies on the average degree of loss. However, I came to the conclusion that to divide the risk premium rate into claims frequency and average degree of damage and to make a separate study of each was not the right way to approach the problem. Both frequency and average damage degree are very sensitive to variations in the number of small claims. The risk premium rate, however, is rather stable because the small claims increase the frequency but diminish the average damage degree accordingly.

II.5 The frequency of small claims showed a strong variation from year to year and from area to area (temporary and geographical variation). These variations could partly be explained by the variation in the frequency of lightning as well as by the different attitude of policyholders to small claims (some of the small claims were reported, some of them not).

II.6 The above constituted good reasons to approach directly the problem of describing the economically relevant factor, namely, the pure risk premium rate. It was possible to show that also here a straight line gave a good description of the data.

We thus obtain for the risk premium rate

where

$$
r(s)=a+b \cdot s
$$

$$
a>0 \text { and } b>0 \text {. }
$$

II.7 There was a characteristic difference between dwellings and farmhouses. For dwellings the constant term independent of value dominated, whereas for farmhouses the term increasing proportionally to the value was the important one.

II.8 The methods developed were, therefore, of particular 
importance for the rating of farmhouses. The straight line here furnished a simple and practical instrument for calculating and for comparing figures from different periods and with different monetary values. The deviation between the data and the straight line was tested by a $x^{2}$-square test [2]. In each size class the sum of the "total losses" was calculated. Every total loss increases that sum by I and the other losses by their respective degree of damage.

II.9 The successful description of the risk premium rate as a function of size by means of a mathematical function has a special importance as it lends stability to the risk premium rate of the highest size classes where the statistical material is small and observations therefore show strong random fluctuations.

II.Io As already mentioned, the linear hypothesis offers a flexible instrument for comparing results from different periods. Changes in the parameters a and b can, in principle, be reduced to one or several of the causes cited below:

a) changes of monetary value

b) changes in the level of risk premiums proportionally in all size classes

c) redistribution with regard to the risk premium rate between bigger and smaller objects.

II.II An inflationary development - ceteris paribus - leaves a unchanged but will lower $b$ in the same degree as the inflation is accepted by the policyholders in the form of raised insurance sums. Changes in the level of risk premiums influence $a$ and $b$ in the same degree. The observed changes in $a$ and $b$ can mainly be reduced to these two causes. Thus a noticeable redistribution regarding the fire risk between bigger and smaller objects has not taken place.

II.r2 Cumulative figures in $\%$ (see page I29).

In other words, during period I $5 \mathrm{I} .4 \%$ of the sums insured in the two smallest size classes produced $20.2 \%$ of the claims amount.

II.I3 In order to facilitate the comparison of the figures from the two periods let us put them in a diagram (period $\mathbf{I}$ is marked 0 and period 2 by $x$; see bottom half of opposite page).

The curve describes both of the periods which means that no redistribution has taken place.

II.I4 In principle it is possible to split the risk premium rate 


\begin{tabular}{|c|c|c|c|c|}
\hline \multirow{2}{*}{\multicolumn{2}{|c|}{$\begin{array}{l}\text { Period I } \\
\text { sums } \\
\text { insured }\end{array}$}} & \multirow[b]{2}{*}{$\begin{array}{c}\text { claims } \\
\text { paid }\end{array}$} & \multicolumn{2}{|c|}{ Period 2} \\
\hline & & & $\begin{array}{l}\text { sums } \\
\text { insured }\end{array}$ & $\begin{array}{c}\text { claims } \\
\text { paid }\end{array}$ \\
\hline I & 30.0 & $9 \cdot 5$ & $23 \cdot 3$ & 6.9 \\
\hline 2 & $5 \mathrm{I} \cdot 4$ & 20.2 & 41.6 & I 6.6 \\
\hline 3 & 64.2 & 28.2 & 53.9 & 24.2 \\
\hline 4 & 72.5 & $37 \cdot 9$ & $63 \cdot 5$ & 33.2 \\
\hline 5 & $8 \mathrm{I} \cdot 4$ & 53.0 & $74 \cdot 5$ & $43 \cdot 4$ \\
\hline 6 & 86.7 & $6 \mathrm{I} .8$ & $8 \mathrm{r} .7$ & 53.1 \\
\hline 7 & 9 I. 8 & 77.0 & 88.4 & 66.7 \\
\hline 8 & 95.0 & 84.6 & 92.6 & 76.7 \\
\hline 9 & 100.0 & 100.0 & 100.0 & I00.0 \\
\hline
\end{tabular}

into the parts emanating from different causes of fire. This has been done and the result was that some causes give an addition to the rate independent of the size thus building up the constant $a$, whilst other causes gave contributions increasing proportionally with size. Thus we have a certain explanation and motivation for $a>o$ in $r(s)=a+b \cdot s[3]$.

I2.I A larger building can at least theoretically be looked

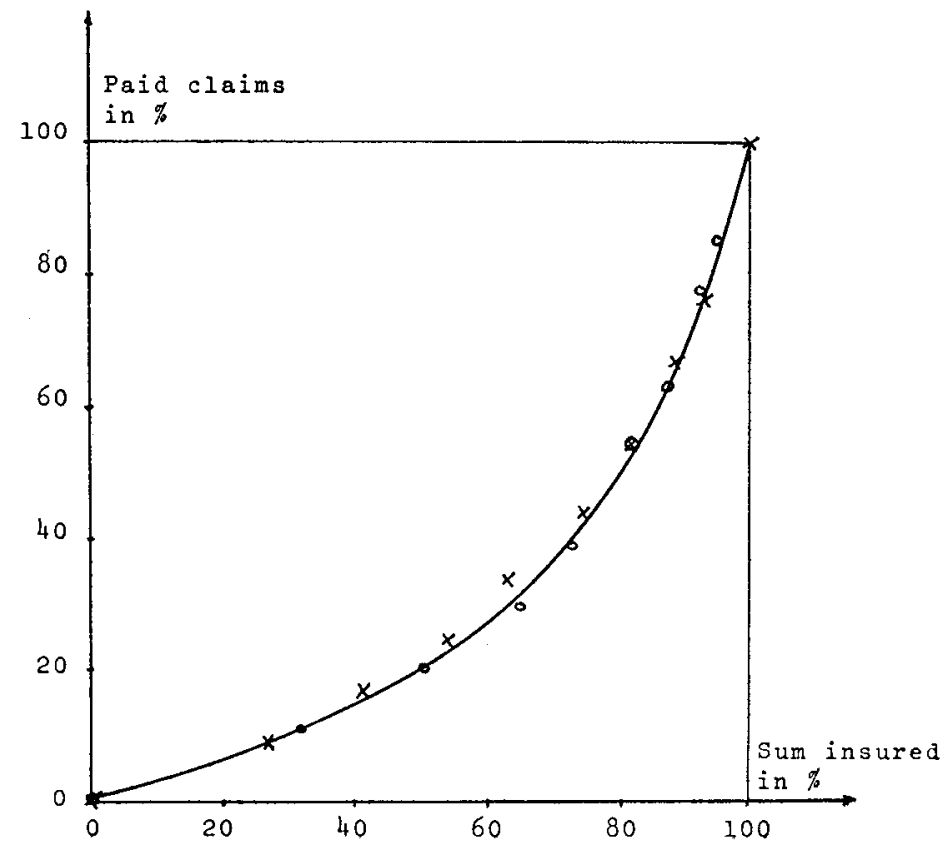


upon as the sum of several smaller buildings. Let us study the case of a division into two buildings. We would expect the claims frequency of the large building to be the sum of the claims frequency of its two parts.

I2.2 It is of particular interest in the above example to have an idea of the risk of contagion as a function of distance, construction of walls and roofs, etc. Inspired by Mr. Berge, who formulated the theoretical basis for such studies already in I937 [6], I made a study in this field in 1947 based on the statistics of an important Danish Fire insurer. The results showed that already a distance of half a meter had a substantial importance, that the frequency of contagion was decreasing rapidly and that contagion at a distance above $20 \mathrm{~m}$ was very rare. The roofs of the two buildings (hard or soft) proved to have a significant influence. Of the 4 combinations (hard-hard, hard-soft, soft-hard, soft-soft) not unexpectedly hard-hard differed favourably and soft-soft unfavourably from the other two.

I2.3 This study was later taken over and fulfilled by none less than Dr. Johansen, first President of the ASTIN Group [I7].

I3.I Let me at this point list some of the formulae which have been suggested for practical use in order to describe claims frequency, average degree of damage and risk premium rate as a function of size (measured in sum insured, value or volume).

claims frequency

$A \cdot V$

$A \cdot V^{\alpha}(\alpha<\mathrm{I})$

$l+k \cdot V$ average degree of damage

$B$

$B V^{-\beta}(\beta<\mathrm{I})$ risk premium rate

$$
\begin{aligned}
& C \cdot V^{\alpha-\beta} \\
& a+b \cdot V
\end{aligned}
$$

I4.I We have not discussed which measures of size are the best: volume, area, value, number of machines, etc. For individual buildings there are strong reasons to believe that the value at risk is a better measure than volume or area.

I4.2 Following d'Addario let us write

$$
\text { frequency } f(V)=A \cdot V^{\alpha}
$$

I4.3 Intuitively the average claim $G$ (not the average degree of damage) is a function which we expect to increase with $V$ and decrease with the area $F$ over which the value $V$ is distributed. 
Let us now assume the following functional relation:

$$
G(V, F)=B \cdot V \cdot F^{-\beta}
$$

I4.4 We thus obtain for the risk premium rate

$$
r(V, F)=\frac{f \cdot G}{V}=A \cdot B \cdot V^{\alpha} \cdot F^{-\beta}
$$

Put the average value per $\mathrm{m}^{2}$ floor area equal to $v=V / F$ and we can thus write either

$$
r(V, F)=A \cdot B \cdot v^{\beta} \cdot V^{\alpha-\beta}
$$

or

$$
r(V, F)=A \cdot B \cdot v^{\alpha} \cdot F^{\alpha-\beta}
$$

I4.5 To the extent that $\mathrm{v}$ is roughly the same from factory to factory within the same industry, the above approach might prove of value. Mr. G. Ramachandran [19] has recently pursued a line similar to the above.

I5.I In a recent talk Mr. Andersson revived Mr. Berge's idea of the 'ideal stone house' and the 'ideal wooden house'. Assuming that the claims frequency

$$
f(V)=A \cdot V
$$

the ideal stone house has an average claim $G(V)=G$ independent of $\mathrm{V}$ or an average degree of damage of

$$
g(V)=G \cdot V^{-1}
$$

This gives a risk premium rate of:

$$
r=A \cdot V \cdot G \cdot V^{-1}=A G=\text { constant }
$$

15.2 The ideal wooden house is defined as one for which all claims are total losses and we thus get:

$$
r=A \cdot V
$$

I5.3 Between these extremes we find the listed categories of risk in the following order:

(ideal wooden house)

Farmhouses of wood

Dwellings of wood

Woodwork in stone houses

Mechanic workshops in stone houses

(ideal stone houses) 


\section{Other branches}

I6. I In Fire insurance the situation is fairly well known and studies indicate that the progression of the risk premium rate can be an important factor.

I6.2 Fire Consequential Loss is expected to follow a pattern similar to that in Fire.

I6.3 Regarding Machinery, experts are convinced that there is a progression, however, no statistical evidence seems to be available.

I6.4 In Water Damage the special circumstances indicate rather a regression.

16.5 For Personal Accident very little is known but we cannot exclude the possibility of a progression.

I6.6 Underwriters of Sea Hull would feel that I tanker of 200,000 tons would need more risk premium than 4 of 50,000 tons, in other words progression on this large size level.

r6.7 In Motor Own Damage, the risk increases with the value of the car, however, not as quickly as the value, that is we have a tendency towards degression.

\section{Loadings for profit and security}

17.I We have seen above that often arguments based on an analysis of the hazards lead to higher rates for larger buildings or risks. What further arguments are there in favour of higher rates for larger risks?

I7.2 The measurement of risk becomes more uncertain for large risks, because they are few in number and inhomogeneous. This uncertainty has to be compensated through special security loadings. Various considerations would here lead to loadings proportional to the dispersion. Let us assume that through such loadings on the risk premium rate the insurer has been able to compensate for the above-mentioned uncertainty as well as for the possible selection against him in the underwriting process which takes place under competition [4].

I8. I To our mind the insurer is entitled to make some further additions to his rates because of the type of services he provides. After all, he is making available his capital and inner reserves for taking over and carrying risks for the insured. As remuneration 
for this service the insurer should receive an addition to the mathematical expectation. On this point, insurer and insured should be able to meet each other.

I8.2 The insured takes out insurance because he prefers to transform a possible loss-uncertain as far as occurrence and size is concerned-into a certain and determined expenditure, i.e. the insurance premium. This "risk aversion" of the insured would make him prepared to pay a premium, which exceeds the mathematical expectation.

I9. I The insurer will also apply some thought to the riskand uncertainty. The acceptance of a large risk, which could produce a high claim represents for him an unpleasant possibility for which he should be compensated by an increased relative profit margin. Intuitively we feel that such a relative profit margin should be proportional to the claims severity or rather to some maximum severity.

I9.2 This leads us to a relative profit loading of

$$
c \cdot M
$$

or an absolute profit loading of

$$
c \cdot E \cdot M
$$

where $\mathrm{E}$ stands for mathematical expectation of the possible claims during the period of consideration and $M$ for some type of maximum severity which we might call PML. $c$ is a constant with the dimension -I (example $c=0 . \mathrm{I} / \$ \mathrm{I}, 000,000)$.

I9.3 The relative profit loading $c \cdot M$ increases linearly with the capacity $(M)$ which is put at disposal by the insurer. We are entitled to refer to the above profit loading as "price for capacity".

20.I Let us look at an underwriter who possesses a portfolio characterized by its annual profit expectation and variance in result. He considers accepting a certain risk with the annual variance $V=\sigma^{2}$. What minimum profit and security loading in the premium shall he ask for if he does not want to worsen his position defined in terms of probability of ruin? The "marginal" risk under consideration is supposed to be independent of the risks already in the portfolio.

20.2 Based on the above and some simplified assumptions a 
minimum profit loading emerges which is proportional to the annual variance $\mathrm{V}$ of the possible outcomes of the risk insured [4].

2I.I Instead of trying to calculate or estimate the variance $V$ we introduce the short cut formula

$$
V \simeq E \cdot M
$$

This formula represents a reasonable approximation, which in most cases is on the safe side.

2 I.2 We thus obtain a price addition

$$
c \cdot V \simeq c \cdot E \cdot M
$$

which is identical with the result in I 9.2 above.

22.I At this point it is also worth mentioning that a model based on a variance $\left(\sigma^{2}\right)$ loading concept explains the advantages of the subdivision and spread of a large risk in the insurance/ reinsurance market. A model based on a pure $\sigma$-loading does not explain this-to our mind-rational behaviour [5].

23.I The idea of a variance loading is certainly not new. Already about I5 years ago, Prof. Knud Hansen, Denmark, was led by his studies to a variance loading. The same result was obtained by Prof. Borch, Norway [Io] by way of the utility theory, whilst Prof. Bühlmann, Switzerland, based on credibility considerations came to the same result [II]. All ways lead to Rome! Other researchers, however, do not like the variance loading, one argument being that the dimension is (dollars) ${ }^{2}$.

24.I We have seen above (I9.3 and 2I.2) that a $\sigma^{2}$ loading can be interpreted as a "price for capacity". As a practical example of such a price for capacity I would like to mention the Swedish Industry Fire Insurance tariff. A special additional premium for larger risks was introduced in 1970 .

\begin{tabular}{ccc}
24.2 & $\begin{array}{c}\text { Maximum Probable Loss (M) } \\
\text { for Fire and Consequential } \\
\text { Loss in million Sw.Kr. }\end{array}$ & $\begin{array}{c}\text { Additional Premium } \\
\text { in } \%\end{array}$ \\
\hline $15-50$ & $\frac{\mathrm{M}}{2}$ \\
$50-70$ & $\begin{array}{c}\mathrm{M}-25 \\
70\end{array}$ \\
\hline
\end{tabular}

For sprinklered risks the above loadings are modified. 
25.I The condition of independency introduced in 20.I can be dropped. Under simplified assumptions regarding the dependence or correlation between the portfolio and the marginal risk, Dr. B. Berliner has shown that a profit loading comes out in which the term $c \cdot V=c \sigma^{2}$ is completed by a term $b \cdot \sigma$ which is proportional to the dispersion [8].

26.I The above considerations taken together thus lead us to a general expression for the premium net of commission equal to

$$
P=E+a E+b \sigma+c \sigma^{2}
$$

Here the term $b \sigma$ takes care of both the uncertainty in the estimation of $E$ and of the correlation factor referred to above. In this connection I would also like to refer to Dr. G. Bergers paper written for this Congress [7].

\section{LIST OF REFERENCES}

[I] D'Addario, R., Considerazioni sul tasso di premio delle assicurazioni incendi. Annali dell' Istituto di Statistica Volume XIVV, Bari I940.

[2] Benktander, G., On the variation of the risk premium with the dimensions of the house within fire insurance. Skandinavisk Aktuarietidskrift, 1953 .

[3] - Contribution of same titel as 2) to the $5_{5}$ th International Congress of Actuaries, New York, 1957.

[4] - Some aspects on reinsurance profits and loadings. The ASTIN Bulletin, Vol. V, Part 3, I97 I.

[5] - A note on profit margin and insurance market capacity. Mitteilungen der Vereinigung schweizerischer Versicherungsmathematiker, Vol. 70, Nr. I, 1970. The Review, Reinsurance Number 1971.

[6] Berge, P. O., Some remarks on rating of fire risks. XIth International Congress of Actuaries, Paris, 1937.

[7] Berger, G., An attempt on the Subject: Profit goal and security loading in risk insurance. International Congress of Actuaries, Oslo, I972.

[8] Berliner, B., Some aspects of standard deviation and variance loadings in reinsurance. Not published.

[9] Blandin, A., Bases techniques de l'assurance contre l'incendie. André Martel, I956.

[Io] Borch, K., The Safety Loading in Reinsurance Premiums. Skand. Aktuarietidskrift, XLIII (I960).

[II] Bühlmann, H., Mathematical Methods in Risk Theory. Springer Verlag, I970.

[12] Centralstället för nordisk ömsesidig brandförsäkringsstatistik, Nordisk brandförsäkringsstatistik. I95 I Vol. I, I953 Vol. 4, I956 Vol. 7, 1957 Vol. 1o, 1963 Vol. 18, 1972 Vol. 30.

[13] Depord, A., Applications de la statistique aux Assurances Accidents et Dommages. Editions Berger-Leurault, Paris, 1967. 
[I4] Einfeld, O., Beitrag zur Statistik der Gebäudefeuerversicherung. XIth International Congress of Actuaries, Paris, 1937.

[15] EkLund, H. J., Om den större eldfarligheten hos stora brandrisker. Nordisk Försäkringstidskrift, Vol. XII, 1932.

[I6] Ferrara, G., Technical and statistical Aspects of the Italian Experience in the Field of Industrial Fire Risks Insurance. Lecture to the Swiss ASTIN-Group 18.Ir.70. Not published.

[17] Johansen, P., On Fire Insurance of Rural Buildings, International Congress of Actuaries, New York, 1957.

[I8] Pestman, P. D., Grote Brandrisico's. Het Verzekerings-Archief, Deel XLVI, Oktober, I969.

[19] Ramachandran, G., Fire Loss Indexes. Fire Research Note 839, September, 1970 .

[20] — Extreme Value Theory and Fire Losses. Fire Research Note 9Io, January, 1972.

[21] Riebesell, P., Einführung in die Sachversicherungs-Mathematik. E. S. Mittler \& Sohn, Berlin, I936.

[22] — Die Mathematik der Feuerversicherung. Berlin, I926.

[23] Sawitsch, S. von, Der Einfluss der Dimensionen des Feuerrisikos auf den Prämiensatz. Zeitschrift für die gesamte Versicherungswissenschaft, 1907 .

[24] Sergowskij, N., Theorie der Feuerversicherung. Erste Böhmische Rückversicherungsbank, Prag, I93I.

[25] Triboulllois, J., L'aggravation des risques par accumulation de valeurs et la tarification des magazins. Conférence Européenne des Sociétés d'Assurances contre l'Incendie. 